\title{
Methylphenidate enhances neural stem cell differentiation
}

\author{
Jasmin Bartl ${ }^{1 *}$, Takatoshi Mori ${ }^{2}$, Peter Riederer ${ }^{3}$, Hiroki Ozawa ${ }^{2}$ and Edna Grünblatt ${ }^{1,3,4}$
}

\begin{abstract}
Background: The psychostimulant methylphenidate (MPH) is the first choice of drug treatment in Attention-Deficit/ Hyperactivity Disorder (ADHD). Since therapy often begins at a time when the brain is still developing and the long-term consequences of MPH are still not fully clarified, we examined the influences of an acute treatment with MPH on the differentiation and proliferation of murine neural stem cells (mNSC).

Findings and conclusion: We found that MPH enhanced neuronal differentiation and inhibited neural proliferation.

Keywords: Methylphenidate, Neural stem cells, Neuronal maturation, Cell proliferation
\end{abstract}

\section{Findings \\ Background}

ADHD is one of the most frequent psychiatric disorders in children and adolescents, with up to $5 \%$ affected worldwide and similar prevalence rates throughout different cultural settings $[1,2]$. It is characterized by developmentally inappropriate levels of inattention, hyperactivity, and/or impulsivity. These core symptoms lead to impairment in home, school, and peer contexts. Stimulants, particularly $\mathrm{MPH}$, are part of the first-line treatment therapies for ADHD [3] and in recent years, the number of prescriptions has increased nearly tenfold [4]. Mechanistically, MPH is a high-affinity inhibitor of the dopamine transporter and a middle-affinity inhibitor to the norepinephrine transporter [5]. However, given the extent of the prescribed use of $\mathrm{MPH}$ [6] exposure to MPH during the early stages of brain development raises some concern for public health due to possible adverse long-term effects such as neurogenesis, neuronal development, or receptor density. It is not clear whether such changes occur; if they do, whether they are related to medication or to the condition itself; if they are caused by medication, whether they have functional significance; and whether any changes are helpful or harmful to mental development. Still, the full mechanism of action of $\mathrm{MPH}$ has not yet been elucidated. A recent study by Lee and colleagues (2012) investigated in vivo the effect of

\footnotetext{
* Correspondence: jasmin.bartl@kjpdzh.ch

${ }^{1}$ Hospital of Child and Adolescent Psychiatry, University of Zurich,

Winterthurerstr. 180, Room L84/86, 8057, Zurich, Switzerland

Full list of author information is available at the end of the article
}

chronically treatment of MPH on cell proliferation and neuronal differentiation in adolescent mice brain tissue [7]. They could demonstrate that $10 \mathrm{mg} / \mathrm{kg}$ MPH treatment for 28 days enhances cell proliferation as well as neuroblast differentiation in contrast to Lagace and colleagues (2006), who detected an inhibition of survival of adult-generated neurons in the temporal hippocampus of adolescent rats after 16 days treatment with $2 \mathrm{mg} / \mathrm{kg}$ of MPH [8]. In concern to the contrasting results and experimental designs of in vivo studies, we investigated the in vitro effect of an acute treatment with MPH using murine neural stem cells (mNSC) originating from hippocampal tissue of embryonic mice E15. NSC are neurosphere-forming cells and can serve as a model for basic neurodevelopmental processes as well as a potential source of neurodegenerative disease [9]. They are clonogenic, self-renewing, and multipotent cells with plasticity to proliferate and to differentiate into all cell types of the central nervous system (CNS) such as glia/astrocytes, oligodendrocytes, and neurons [10]. Such a model enables the study of neuronal development, differentiation, and neuronal cell death mechanisms in vitro.

\section{Material and methods}

Murine neural stem cell (mNSC) sphere culturing mNSCs were derived from the hippocampus tissue of albino mouse (Charles River, Japan) embryos on embryonic day 15. Cells were cultured in a medial hormone mix (MHM) with $10 \mu \mathrm{g} / \mathrm{ml}$ epidermal (EGF; Sigma aldrich, Japan, Cat-No: SRP3196) and $10 \mu \mathrm{g} / \mathrm{ml}$ basic fibroblast growth factors (bFGF; Sigma aldrich, Japan, Cat-No: F5392) 
for six days at $37^{\circ} \mathrm{C}$ and $5 \% \mathrm{CO} 2$. After six days, the grown NSC spheres were harvested and prepared for differentiation and/or proliferation studies (for methods, see below).

\section{Differentiation study}

mNSC spheres were collected and plated on a $30 \mu \mathrm{g} / \mathrm{ml}$ poly-l-lysine (Sigma aldrich, Japan, Cat-No: P1274) and 20 $\mu \mathrm{g} / \mathrm{ml}$ laminine (Invitrogen, Japan, Cat-No: 23017-015) coated 8-well glass cover-slip and incubated for another 4 days. Each well had a final concentration of $22.8 \times 104$ cells/ml cultured in MHM containing 1\% fetal bovine serum (FBS) and without EGF and bFGF. The cells were treated directly after seeding to the cover-slip using different concentration (0 nM, $1 \mathrm{nM}, 10 \mathrm{nM}, 100 \mathrm{nM}$ ) of methylphenidate (MPH; Sigma aldrich, Japan, Cat-No: M2892). On the last day, cells were fixed with $4 \%$ paraformaldehyde (Fluka, Japan, Cat-No: 76240) for 20 minutes at room temperature (RT) and stained with different antibodies (see "Immunocytochemistry").

\section{BrdU incorporation}

The proliferation of NSC was identified by in vitro labeling with the thymidine analog 5-bromo-2-desoxyuridine (BrdU; Wako, Japan, Cat-No: 023-15563). NSC spheres were collected and plated on coated 8-well glass cover-slip and incubated for $24 \mathrm{~h}$. Each well had a final concentration of $22.8 \times 104$ cells/ml cultured in MHM, containing EGF and bFGF and without FBS. The cells were treated with different concentration of $\mathrm{MPH}(0 \mathrm{nM}, 1 \mathrm{nM}, 10 \mathrm{nM}$, $100 \mathrm{nM}$ ). After $24 \mathrm{~h}, \mathrm{BrdU}$ was added to each well to reach a final concentration of $10 \mu \mathrm{M}$ and incubated for $4 \mathrm{~h}$ at RT. Before BrdU immunostaining, DNA was denatured and the nucleus-membrane was broken by treating cells with $2 \mathrm{M} \mathrm{HCL}$ for $35 \mathrm{~min}$ at RT; afterward, cells were rinsed with $1 \%$ phosphate buffer saline (PBS), followed by treatment with sodium borate $(\mathrm{pH}=8.5)$ for $10 \mathrm{~min}$ at $\mathrm{RT}$ for the neutralization of HCL. The prepared cells were stained against BrdU (see "Immunocytochemistry").

\section{Immunocytochemistry}

Fixed and prepared cells were stained for differentiation studies with rabbit monoclonal antibody against glial fibrillary acidic protein (GFAP; 1:200, Sigma aldrich, USA, Cat-No: C4546) and/or with mouse monoclonal antibody against $\beta$-tubulin III (Tuj 1; 1:300, Sigma aldrich, USA, Cat-No: T3952) overnight at $4^{\circ} \mathrm{C}$. For proliferation studies, cells were stained with rat monoclonal antibody against BrdU (1:100, Accurate Chemical \& Scientific, Japan, Cat-No: OBT0030) overnight at $4^{\circ} \mathrm{C}$. In both studies, fixed cells were also stained with Hoechst 33258 (1:100; Invitrogen, Cat-No: H3569) for $15 \mathrm{~min}$ at RT to visualize the cell nuclei. After overnight incubation, the primary antibodies were visualized with secondary antibodies against rabbit, mouse, or rat conjugated to the following fluorochromes: Alexa Fluor ${ }^{\circledR}-488$ and Alexa Fluor $^{\circledR}-555$ (Life Technologies, Japan).

\section{Statistical analysis}

The stainings were analyzed for the cell count of astrocytes, immature neurons and proliferated cells in comparison to the total number of cells using the Mann-

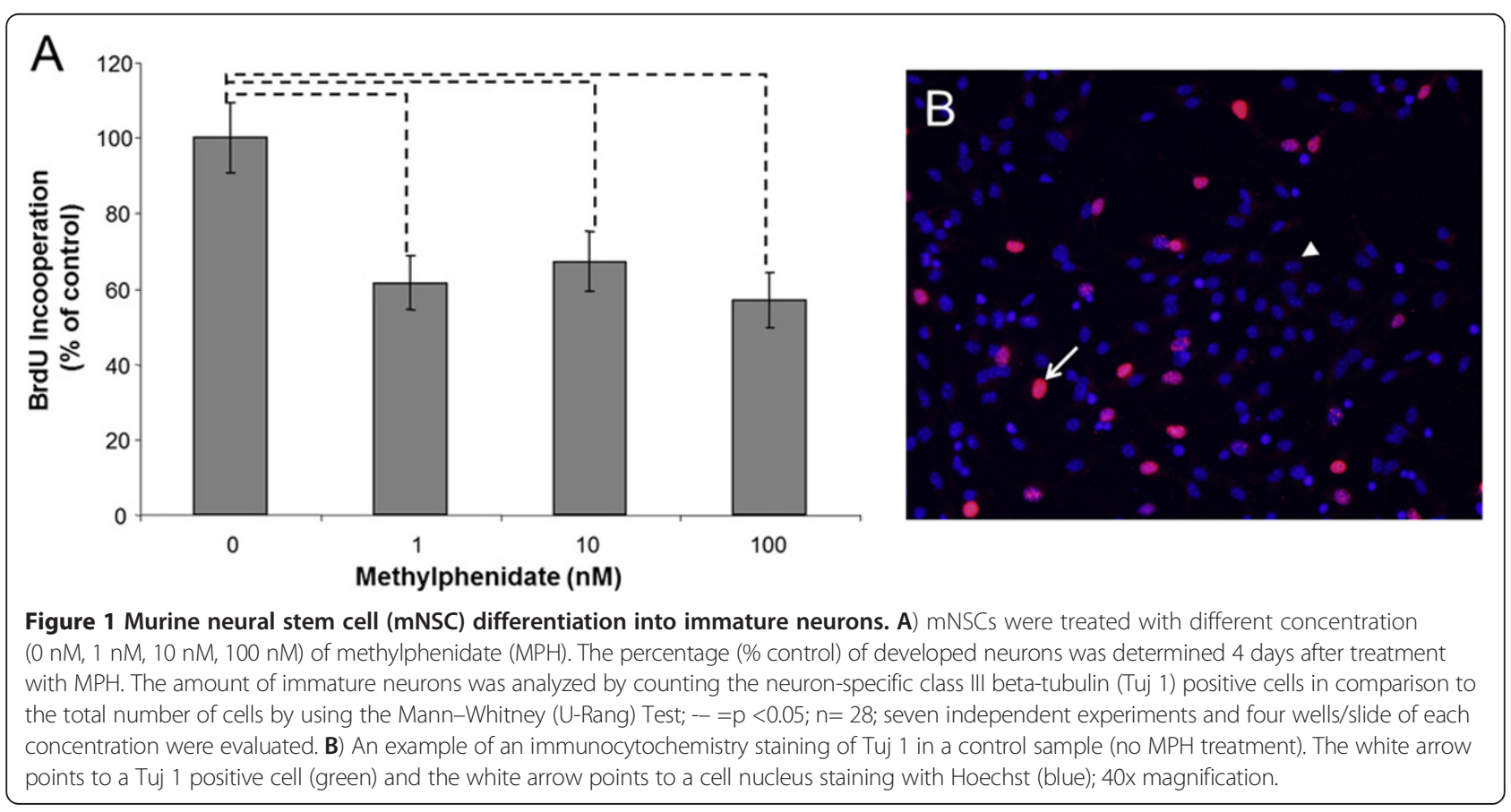




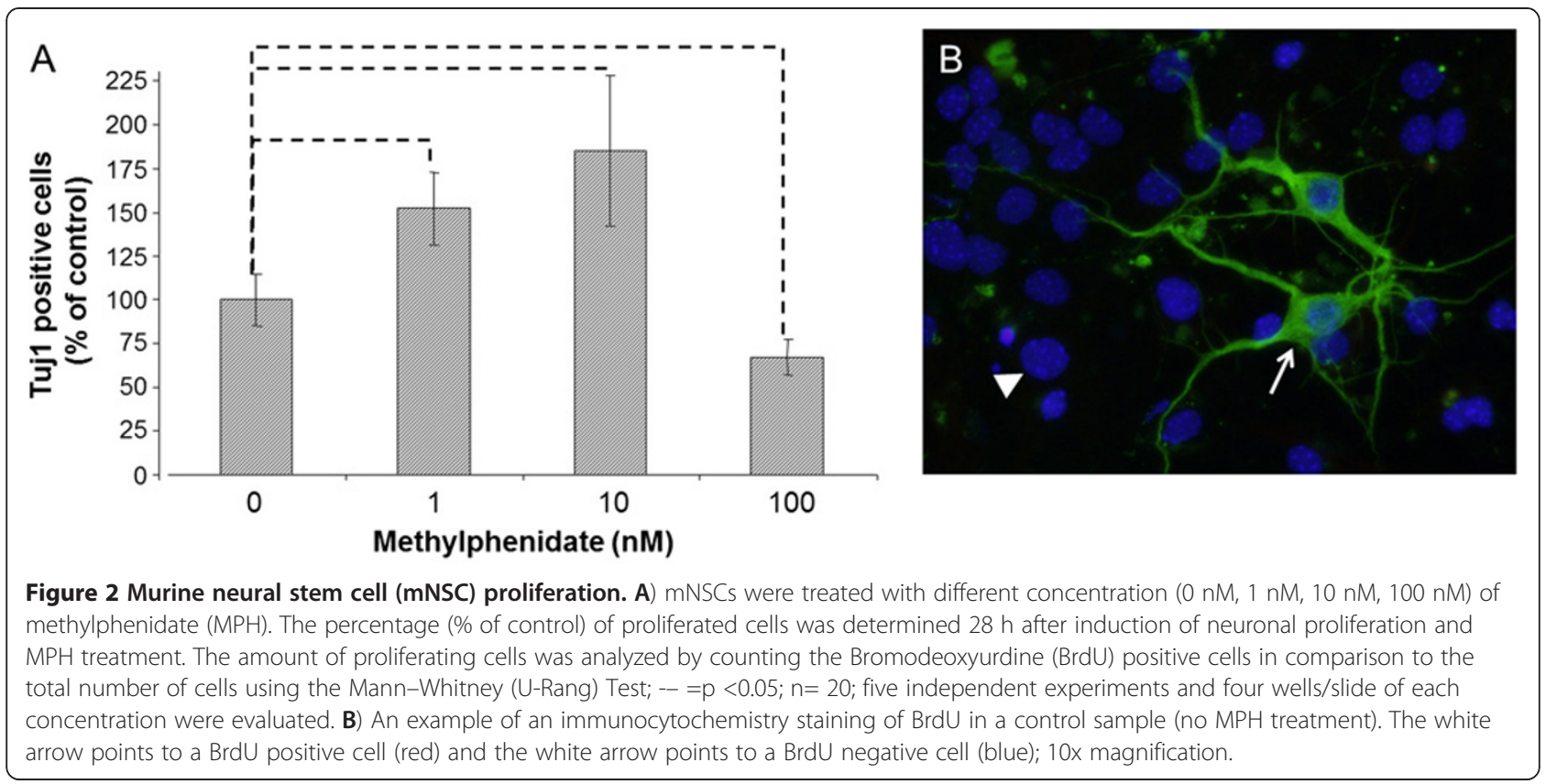

Whitney (U-Rang) Test in the StatView software program (Stat View 5.0. software, SAS Institute Inc. Cary, NC, USA). A p-value $<0.05$ was set as significant. There were at least five independent experiments, and four wells per slide were analyzed. In each case, the total amount of Hoechst stained cells/well were manually counted, and afterward, either BrdU positive, GFAP positive, or Tuj 1 positive cells were counted and the percentage of positive cells to the total amount was calculated. In the proliferation and differentiation studies a comparison of the treated mNSC to the control mNSC (MPH untreated) was done.

\section{Results}

After $1 \mathrm{nM} \mathrm{MPH}$ treatment, the neuronal differentiation was significantly enhanced, and 53\% more immature neurons could be detected compared to untreated mNSCs (Figure 1). After $10 \mathrm{nM}$ of $\mathrm{MPH}$, the enhancement of neuronal differentiation was over $80 \%$, but the highest

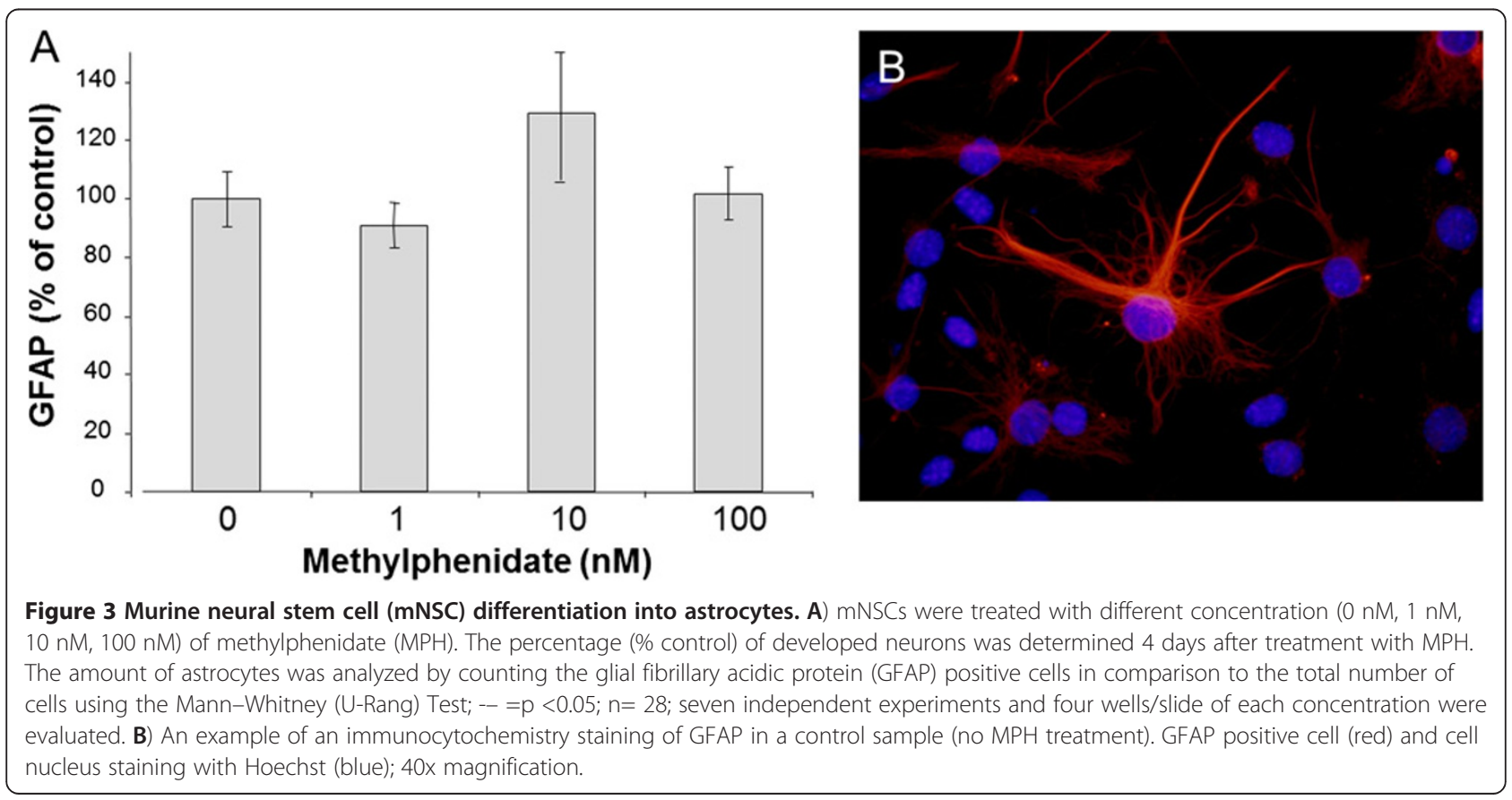


dose of MPH (100 nM) showed a reduction of 39\% (Figure 1). In contrast, all tested concentration (1-100 nM) of $\mathrm{MPH}$ inhibited the proliferation of mNSC (Figure 2). For neuronal maturation, it is important that the neural stem cell stops proliferating and starts the outgrowth of neuritis to develop into full neurons, which seems to be enhanced by the concentration of $1 \mathrm{nM}$ and $10 \mathrm{nM}$ of used MPH. In contrasts, MPH treatment at the given dose range did not significant affect the development of astrocytes in comparison to untreated mNSC (Figure 3).

\section{Availability of supporting data Discussion}

In this work, we presented the effects of low doses (1-100 nM) MPH treatment at mNSC proliferation and neuronal maturation. In 2010 we could already demonstrate, that especially low doses of MPH have the strongest impact on gene expression and cell proliferation in neuronal cell line culture [11]. Our results suggest that MPH seems to support neuronal maturation in a specific range and enhances the neuronal outcome. This hypothesis fits the fact that children with ADHD have atypical or typical but delayed maturation of the prefrontal cortex [12]. Structural imaging in ADHD provides evidence for a global maturational delay based on reduced gray and white matter volume and cortical thickness in ADHD relative to controls through childhood and adolescence [13,14]. MPH seems to balance this retardation of neuronal development, but the mechanism of action is still not known and needs further investigation [15]. However, few studies have addressed the structural correlates of psychostimulant treatment. Castellanos et al. (2002) found that prior treatment with psychostimulants in children with ADHD was associated at study entry with greater white matter lobar volumes relative to stimulant-naive children with ADHD and volumes that lie closer to the range of their typically developing counterparts, suggesting a neuroprotective effect [16]. An independent study of 30 children with ADHD examining the regions implicated in the pathogenesis of the disorder, similarly, found that treatment with psychostimulants was associated with a more normative volume of the caudate and anterior cingulate cortex [17]. Additionally, the group of Antonello Bonci (2010) recently showed that MPH can influence neuronal plasticity in the amygdale and, thus, can improve learning performance [18]. Within the inherent limitations of a preliminary study, we find great influences of MPH on neuronal maturation, which may prove activity-dependent neuronal plasticity. However, one has to take into account that this in vitro experiment did not investigate any $\mathrm{MPH}$ influences on neurogenesis, which can be another possible mechanism of action of MPH.

\section{Abbreviations}

ADHD: Attention-Deficit/Hyperactivity Disorder; bFGF: basic fibroblast growth factor; BrdU: 5-bromo-2-desoxyuridine; CNS: Central nervous system;
$\mathrm{CO}_{2}$ : Carbon dioxid; EGF: Epidermal growth factor; FBS: Fetal bovine serum; GFAP: Glial fibrillary acicid protein; HCL: Hydrochloric acid; MHM: Medial hormone mix; mNSC: Murine neural stem cell; MPH: Methylphenidate; nM: Nano mol; RT: Room temperature; Tuj1: Beta tubulin III.

\section{Competing interests}

The authors declare no competing financial or non-financial interests.

\section{Authors' contributions}

JB prepared NSCs, carried out the experiments, performed statistical analyses and wrote the manuscript. TM helped design the experiments and supervised JB in material and methods. PR designed the experiments and conceived the project. $\mathrm{HO}$ contributed reagents and supervised JB in Nagasaki, Japan. EG conceived the project, designed experiments, helped write the manuscript and reviewed the statistical analyses. All authors read and approved the final manuscript.

\section{Acknowledgments}

Jasmin Bartl was supported by the "Deutscher Akademischer Austausch Dienst (DAAD)" with a travel grant to Japan. The DAAD had no further role in study design; in the collection, analysis and interpretation of data; in the writing of the report; and in the decision to submit the paper for publication.

\section{Author details}

${ }^{1}$ Hospital of Child and Adolescent Psychiatry, University of Zurich, Winterthurerstr. 180, Room L84/86, 8057, Zurich, Switzerland. 'Division of Neuropsychiatry, Nagasaki University Graduate School of Biomedical Sciences, Nagasaki, Japan. ${ }^{3}$ Department of Psychiatry, Psychosomatics and Psychotherapy, University Hospital of Wuerzburg, Wuerzburg, Germany. ${ }^{4}$ Neuroscience Center Zurich, University of Zurich and ETH Zurich, Switzerland.

Received: 23 November 2012 Accepted: 18 January 2013 Published: 23 April 2013

\section{References}

1. Biederman J, Faraone SV: Attention-deficit hyperactivity disorder. Lancet 2005, 366(9481):237-248.

2. Polanczyk G, de Lima MS, Horta BL, Biederman J, Rohde LA: The worldwide prevalence of ADHD: a systematic review and metaregression analysis. Am J Psychiatry 2007, 164(6):942-948.

3. Gunther T, Herpertz-Dahlmann B, Konrad K: Sex differences in attentional performance and their modulation by methylphenidate in children with attention-deficit/hyperactivity disorder. J Child Adolesc Psychopharmacol 2010, 20(3):179-186.

4. Schubert I, Koster I, Lehmkuhl G: The changing prevalence of attentiondeficit/hyperactivity disorder and methylphenidate prescriptions: a study of data from a random sample of insurees of the AOK Health Insurance Company in the German State of Hesse, 2000-2007. Dtsch Arztebl Int 2010, 107(36):615-621.

5. Han DD, Gu HH: Comparison of the monoamine transporters from human and mouse in their sensitivities to psychostimulant drugs. BMC Pharmacol 2006, 6:6.

6. Bogle KE, Smith BH: Illicit methylphenidate use: a review of prevalence, availability, pharmacology, and consequences. Curr Drug Abuse Rev 2009, 2(2):157-176.

7. Lee $\mathrm{TH}$, Lee $\mathrm{CH}$, Kim IH, Yan BC, Park JH, Kwon SH, Park OK, Ahn JH, Cho JH, Won MH, Kim SK: Effects of ADHD therapeutic agents, methylphenidate and atomoxetine, on hippocampal neurogenesis in the adolescent mouse dentate gyrus. Neurosci Lett 2012, 524(2):84-88.

8. Lagace DC, Yee JK, Bolanos CA, Eisch AJ: Juvenile administration of methylphenidate attenuates adult hippocampal neurogenesis. Biol Psychiatry 2006, 60(10):1121-1130.

9. Tropepe V, Sibilia M, Ciruna BG, Rossant J, Wagner EF, van der Kooy D: Distinct neural stem cells proliferate in response to EGF and FGF in the developing mouse telencephalon. Dev Biol 1999, 208(1):166-188.

10. Onorati M, Camnasio S, Binetti M, Jung CB, Moretti A, Cattaneo E: Neuropotent self-renewing neural stem (NS) cells derived from mouse induced pluripotent stem (iPS) cells. Mol Cell Neurosci 2010, 43(3):287-295. 
11. Bartl J, Link P, Schlosser C, Gerlach M, Schmitt A, Walitza S, Riederer P, Grunblatt E: Effects of methylphenidate: the cellular point of view. Atten Defic Hyperact Disord 2010, 2(4):225-232.

12. Vaidya CJ: Neurodevelopmental abnormalities in ADHD. Curr Top Behav Neurosci 2012, 9:49-66.

13. Seidman $\mathrm{L}$, Valera $\mathrm{EM}$, Makris $\mathrm{N}$ : Structural brain imaging of attentiondeficit/hyperactivity disorder. Biol Psychiatry 2005, 57(11):1263-1272.

14. Mostofsky SH, Rimrodt SL, Schafer JG, Boyce A, Goldberg MC, Pekar JJ, Denckla MB: Atypical motor and sensory cortex activation in attentiondeficit/hyperactivity disorder: a functional magnetic resonance imaging study of simple sequential finger tapping. Biol Psychiatry 2006, 59(1):48-56.

15. Rubia K, Halari R, Christakou A, Taylor E: Impulsiveness as a timing disturbance: neurocognitive abnormalities in attention-deficit hyperactivity disorder during temporal processes and normalization with methylphenidate. Philos Trans R Soc Lond B Biol Sci 2009, 364(1525):1919-1931.

16. Castellanos FX, Lee PP, Sharp W, Jeffries NO, Greenstein DK, Clasen LS, Blumenthal JD, James RS, Ebens CL, Walter JM, Zijdenbos A, Evans AC Giedd JN, Rapoport JL: Developmental trajectories of brain volume abnormalities in children and adolescents with attention-deficit /hyperactivity disorder. JAMA 2002, 288(14):1740-1748.

17. Semrud-Clikeman M, Pliszka SR, Lancaster J, Liotti M: Volumetric MRI differences in treatment-naive vs chronically treated children with ADHD. Neurology 2006, 67(6):1023-1027.

18. Tye KM, Tye LD, Cone JJ, Hekkelman EF, Janak PH, Bonci A: Methylphenidate facilitates learning-induced amygdala plasticity. Nat Neurosci 2010, 13(4):475-481.

doi:10.1186/2049-9256-1-5

Cite this article as: Bartl et al:: Methylphenidate enhances neural stem cell differentiation. Journal of Molecular Psychiatry 2013 1:5.

\section{Submit your next manuscript to BioMed Central and take full advantage of:}

- Convenient online submission

- Thorough peer review

- No space constraints or color figure charges

- Immediate publication on acceptance

- Inclusion in PubMed, CAS, Scopus and Google Scholar

- Research which is freely available for redistribution 